DOI 10.37882/2500-3682.2021.06.02

\title{
ВЗАИМОСВЯЗЬ ЦЕННОСТЕЙ И УДОВЛЕТВОРЕННОСТИ БРАКОМ
}

\section{RELATIONSHIP BETWEEN VALUES AND MARITAL SATISFACTION}

\section{A. Bugaeva}

Summary: The article is devoted to one of the urgent problems of studying the family based on family values and satisfaction with marriage. A brief review of scientific research conducted by the author showed that at the present stage of development of psychological science and practice, it is necessary to consider the issue of the relationship between values and satisfaction with marriage. Having studied the essence of the problem, the author monitored the relationship between values and satisfaction with marriage, the purpose of which was to study the relationship between satisfaction with marriage and individual and family values in men and women who are married. The monitoring was carried out in several stages. At the first stage, the author investigated the nature of the relationship between certain spheres of life. As a methodology for measuring the nature of the ratio of certain areas of life, as a value, with their availability in implementation, the methodology «The level of ratio of» value «and» availability «in various spheres of life was used. In the second step, the author measured family values. A test questionnaire by A.N. Volkova «Role expectations and ambitions in marriage.» At the third stage, the author identified the level of satisfaction with marriage among men and women. To identify the level of satisfaction with marriage in men and women, a test questionnaire of satisfaction with marriage was used (V.V. Stolin, T.L. Romanova, G.P. Butenko). Statistical data processing was carried out - Pearson's correlation analysis method between the results of the methodology "the level of correlation of "value" and "availability", "ROP" and the test questionnaire "satisfaction with marriage" in two groups (men and women). The last stage of the study was to identify the relationship between indicators of family values of men and women in marriage with the level of satisfaction with marriage. The results of the study are beyond doubt, as they are confirmed by a complex of scientific research methods.

Keywords: family, family values, satisfaction with marriage, expectations and claims in marriage.

\author{
Бугаева Анна Михайловна \\ Аспирант, Кубанский государственный университет, \\ Краснодар \\ kalinskaia@mail.ru
}

Аннотация: Статья посвящена одной из актуальных проблем изучения семьи на основе семейных ценностей и удовлетворенности браком. Краткий обзор научных исследований, проведенный автором, показал, что на современном этапе развития психологической науки и практики необходимо рассмотреть вопрос о взаимосвязи ценностей и удовлетворенности браком. Изучив суть проблемы, автор провел мониторинг взаимосвязи ценностей и удовлетворенности браком, целью которого было изучение взаимосвязи удовлетворенности браком с индивидуальными и семейными ценностями у мужчин и женщин, состоящих в браке. Мониторинг проводился в несколько этапов. На первом этапе автор исследовал характер соотношения определенных сфер жизни. В качестве методики для измерения характера соотношения определенных сфер жизни, как ценности, с их доступностью в реализации была использована методика «Уровень соотношения «ценности» и «доступности» в различных жизненных сферах». На втором этапе автор измерял семейные ценности. В качестве методики измерения семейных ценностей был использован тест-опросник А.Н. Волковой «Ролевые ожидания и притязания в браке». На третьем этапе автор выявил уровень удовлетворенности браком у мужчин и женщин. Для выявления уровня удовлетворенности браком у мужчин и женщин, использовался тест-опросник удовлетворенности браком (В.В. Столин, Т.Л. Романова, Г.П. Бутенко). Была проведена статистическая обработка данных - метод корреляционного анализа Пирсона между результатами методики «уровень соотношения «ценности» и «доступности», «РОП» и тест-опросником «удовлетворенности браком» в двух группах (мужчины и женщины). Последний этап исследования заключался в выявлении связи показателей семейных ценностей мужчин и женщин в браке суровнем удовлетворенности браком. Результаты исследования не вызывают сомнения, так как подтверждены комплексом научных методов исследования.

Ключевые слова: семья, семейные ценности, удовлетворенность браком, ожидания и притязания в браке.

ний и норм поведения. Это живой организм с собственными жизненными циклами, кризисами, изменениями и трансформациями $[1,2,4,8,9]$.

Краткий обзор научных исследований показал, что вопросами изучения семьи занимались многие зарубежные и отечественные психологи-исследователи (Ю.П. Азаров, С.И. Голод, А.А. Клецина, В.Н. Дружинина, А.Я. Варга, А.Г. Лидерс, А.И. Антонов, Т.А. Гурко, С. Кунц, М. Боуэн и др.). Мы согласны с мнением Е.В. Киселевой, что особенно актуальной проблема исследования семьи стала с конца 90-х годов XX века, в связи с новыми куль- 
турно-историческими реалиями и переходом от одной социальной системы к другой [8].

Удовлетворенность браком в своих работах освещали (Н.Г. Юркевич, Ю.А. Алешина, В.А. Сысенко, П. Кериг, М. Дуенди, Т.В. Свадьбина, О.В. Егорова, Т.В. Андреева, Л.Б. Шнейдер, В.А. Терехина, Ю.Е. Темиргалиева и др.).

Алешина Ю.А. удовлетворенность браком считает неким мерилом, субъективной оценкой каждого из партнеров о характере их взаимоотношений [1]. Баландина Л.Л. удовлетворенность браком рассматривает на основе эмоционально-оценочных отношений в семье, связанных с реализацией потребностей в любви, открытости, общении, поддержке, заботе и взаимопонимания [2].

Ю.С. Котельникова считает, что большое влияние на удовлетворенность браком оказывают различные факторы: - характер взаимоотношений между супругами; - личностные особенности каждого супруга; - мотивы вступления в брак; - совпадение/несовпадение ценностных ориентаций в семье. Гармоничный брачный союз во многом зависит от того, какие ценности содержит каждый из супругов. В этом месте тесно переплетаются ожидания партнеров с адекватным ролевым поведением, а также ценностными ориентациями индивидуальными и общими с партнером [9].

О.А. Шаваева считает, что, в современном обществе происходит выпадение семейных ценностей из системы ценностей индивида и это глобально отражается на росте разводов [12].

За последние три десятка лет взаимоотношения между мужчинами и женщинами изменились масштабнее, чем за предыдущие три тысячи лет, необратимая и существенная трансформация произошла с институтом брака и семьи [11]. И каждый ученый на междисциплинарном уровне должен задать себе вопрос: «Что мы знаем о том, как помочь каждой семье минимизировать проблемы и укрепить ее сильные стороны?» [10].

Мы же разделяем мнение Т.А. Гурко о том, что в настоящее время институт семьи стремительно претерпевает изменения и трансформацию, и, никто не знает, как жить в новом мире после пандемии в параллели, идущей с другими мировыми кризисами и изменениями, в частности финансовыми [6].

Таким образом, обзор научной и специальной литературы позволил сделать вывод о том, что на протяжении многих десятилетий проблеме изучения семьи и удовлетворенности браком посвящались работы многих авторов. Мы же считаем, что на современном этапе развития психологической науки и практики необхо- димо рассмотреть вопрос о взаимосвязи ценностей и удовлетворенности браком, поскольку данный аспект проблемы недостаточно рассматривался в научных исследованиях.

В связи с этим, проблема взаимосвязи ценностей и удовлетворенности браком является актуальной и приобретает научную значимость.

«Семейные ценности - это аспекты семейной жизни, отражающие основные функции современной семьи: организация бытового потребления, интимные отношения, организация досуга, партнерские отношения, воспитание детей, эстетические ценности»[3].

Наиболее полную систематизацию семейных ценностей, полученную в исследованиях разных авторов, создал Т.А. Гурко:

- экономические и социально-демографические характеристики семьи: совокупность и величина семейного бюджета, возраст супругов, количество детей в семьи и др.; - характеристики вне семейной сферы жизнедеятельности супругов: взаимоотношения с ближайшим социальным окружением, профессиональная сфера, открытость/закрытость семейной системы и др.; - установки и поведение супругов в основных сферах семейной жизни: хозяйственно-бытовые обязанности, тождественность установок в сфере семейной жизни, досуг и др.; - характеристика межсупружеских отношений: эмоционально-нравственные ценности, любовь и уважение к партнеру, общие взгляды и ценности, супружеская верность [5].

«Супружеские отношения относятся к одному из видов интеракции, причиной которого является согласованность ценностно-смысловых координат жизненных миров. Объединение людей в браке связано с естественной перестройкой их ценностей и становления сосистемы их семейных ценностей» [7].

Ценностные ориентации любого индивида со временем видоизменяются вместе с семейными ценностями и являются одним из важнейших компонентов уровня удовлетворенности браком. Ведь если мы не знаем ценностные ориентации своего партнера и не обозначаем свои, мы сталкиваемся с несовпадением наших ценностей или значимости в их иерархии, что неминуемо приводит к семейным конфликтам.

Поэтому для нас важным было понять, есть ли взаимосвязь между удовлетворенностью браком и индивидуальными и семейными ценностями? В каких сферах ценностных ориентаций есть эти связи, и как именно они влияют на мужчин и женщин в браке? 
Изучив суть проблемы, мы сочли возможным, провести мониторинг взаимосвязи ценностей и удовлетворенности браком, целью которого было изучение взаимосвязи удовлетворенности браком с индивидуальными и семейными ценностями у мужчин и женщин, состоящих в браке.

В качестве респондентов в исследовании приняли участие 120 человек (60 пар) находящихся в официальном браке (до 5 лет). Возраст респондентов составил от 28 до 36 лет.

\section{Мониторинг проводился в несколько этапов.}

На первом этапе мы исследовали характер соотношения определенных сфер жизни. В качестве методики для измерения характера соотношения определенных сфер жизни, как ценности, с их доступностью в реализации была использована методика «Уровень соотношения «ценности» и «доступности» в различных жизненных сферах» [13] (статистическая обработка данных расчет средних тенденций, градация баллов равна от 0 до 12).

Методика включает 12 категорий: - активная деятельная жизнь; - здоровье (физическое и психическое здоровье); - интересная работа; - красота природы и искусства; - любовь (духовная и физическая близость с любимым человеком); - материально-обеспеченная жизнь (отсутствие материальных затруднений); - наличие хороших и верных друзей; - уверенность в себе; - познание (возможность расширения своего образования, кругозора, интеллектуальное развитие); - свобода как независимость в поступках и действиях; - счастливая семейная жизнь; - творчество (возможность творческой деятельности).

Результаты исследования соотношений определенных сфер жизни с доступностью их реализации у мужчин и женщин, находящихся в браке представлены в табл. 1.

При сравнении индивидуальных ценностей у мужчин и женщин, находящихся браке были выявлены следующие различия. Для женщин, находящихся в браке значимыми являются следующие сферы: - здоровье (физическое и психическое здоровье(3,9)); - красота природы и искусства $(3,76)$; - ценности счастливой семейной жизни $(3,26)$. В иерархии индивидуальных ценностей именно эти сферы оказались наиболее важны для женщин.

Результаты мужчин значительно отличаются. Однако следует отметить, что мужчины так же, как и женщины заинтересованы в своем здоровье $(4,33)$, но менее включены в другие сферы жизни в отличие от женщин.

На втором этапе мы измеряли семейные ценности. В качестве методики измерения семейных ценностей был использован тест-опросник А.Н. Волковой «Ролевые ожидания и притязания в браке» [4]. Опросник содержит 7 сфер семейных ценностей (градация от 0 до 9 баллов): - интимно-сексуальная; - личностная идентификация; хозяйственно-бытовая; - родительско-воспитательская; - социальная активность; - эмоционально-психотерапевтическая; - сфера внешней привлекательности.

Результаты исследования выраженности семейных ценностей у мужчин и женщин, находящихся в браке представлены в табл. 2.

Результаты показали, что для обеих категорий респондентов наиболее важными оказались следующие ценности: - личностная идентификация у мужчин $(6,7)$, у женщин $(6,56)$ - это говорит о том, что психологическая включенность партнера играет большую роль, как для мужчин, так и для женщин; - родительско-воспитательская ценность у мужчин $(7,13)$, у женщин $(6,3)$. Стоит отметить, что показатель мужчин выше, чем показатель женщин, но для обеих категорий респондентов значима личная реализация в этой сфере; - сфера социальной активности, занимает у мужчин $(6,55)$ и женщин $(6,91)$ значимое место, а это значит, что неизбежно становится важной социальная активность. Также в обеих группах значимой является эмоционально-психотерапевтиче-

Таблица 1.

Средние значения выраженности индивидуальных ценностей у мужчин и женщин, находящихся в браке

\begin{tabular}{|l|c|c|c|c|c|c|c|c|c|c|c|c|}
\hline & 1 & 2 & 3 & 4 & 5 & 6 & 7 & 8 & 9 & 10 & 11 & 12 \\
\hline Мужчины & $-0,96$ & 4,33 & $-0,83$ & $-2,96$ & 1,26 & 2,73 & 0,13 & $-1,2$ & 1,13 & $-0,7$ & 1,4 & $-1,9$ \\
\hline Женщины & $-2,1$ & 3,9 & $-1,53$ & $-3,76$ & 2,16 & 2,36 & $-0,73$ & 1,36 & $-1,86$ & $-0,1$ & 3,26 & $-2,5$ \\
\hline
\end{tabular}

Таблица 2.

Средние значения выраженности семейных ценностей у мужчин и женщин, находящихся в браке

\begin{tabular}{|l|c|c|c|c|c|c|c|}
\hline & 1 & 2 & 3 & 4 & 5 & 6 & 7 \\
\hline Мужчины & 5,2 & 6,7 & 5,55 & 7,13 & 6,55 & 6,56 & 5,91 \\
\hline Женщины & 4,76 & 6,56 & 5,86 & 6,3 & 6,91 & 6,95 & 6,45 \\
\hline
\end{tabular}


ская ценность (мужчины $(6,56)$, женщины $(6,95))$. Эти данные говорят о том, что и мужчинам, и женщинам необходима эмоциональная поддержка от партнера в своем браке. Следует отметить, что для женщин, находящихся в браке высокой ценностью является внешняя привлекательность, о чем свидетельствует средний показатель этой сферы $(6,45)$, в то время как для мужчин эта ценность не так важна.

На третьем этапе мы выявили уровень удовлетворенности браком у мужчин и женщин. Для выявления уровня удовлетворенности браком у мужчин и женщин, использовался тест-опросник удовлетворенности браком (В.В. Столин, Т.Л. Романова, Г.П. Бутенко) [1].

Результаты исследования уровня удовлетворенности браком у мужчин и женщин, находящихся в браке представлены в табл. 3.

Таблица 3.

Средние значения выраженности уровня удовлетворенности браком у мужчин и женщин, находящихся в браке

\begin{tabular}{|c|c|}
\hline Мужчины & 36,8 \\
\hline Женщины & 35,9 \\
\hline
\end{tabular}

При сравнении среднего показателя уровня удовлетворенности браком в двух группах были выявлены следующие результаты: мужчины $(36,8)$, женщины $(35,9)$. Результаты свидетельствует о том, что мужчины более удовлетворены своим браком, чем женщины.

Результаты трех этапов исследования позволили сделать вывод о том, что семейные ценности у мужчин и женщин отличаются и имеют свою специфику. Мужчины более довольны своим браком чем женщины, но также, как и женщины заинтересованы своим здоровьем, об этом говорит высокий уровень показателя этой ценности. Между тем, для мужчин, как и для женщин является значимым психологическая включенность в партнера, реализация в сфере родительства, поддержка со стороны партнера и возможность социальной активности. Следует отметить, что для женщин важна внешняя привлекательность, в то время как мужчины меньше внимания уделяют внешности и эта ценность для них не так важна.

Следующий этап исследовательской работы заключался в выявлении корреляционной зависимости взаимосвязи характера соотношения определенных сфер жизни, с доступностью их реализации у мужчин и женщин с уровнем удовлетворенности браком. Была проведена статистическая обработка данных - метод корреляционного анализа Пирсона между результатами методики «уровень соотношения «ценности» и «доступности», «РОП» и тест-опросником «удовлетворенности браком» в двух группах (мужчины и женщины).

Результаты корреляционного анализа представлены в табл. 4.

Критические значения коэффициента корреляции Пирсона для 120 человек равен 0,20.

Приведенные результаты, позволяют сопоставить выраженность индивидуальных ценностей у мужчин и женщин, находящихся в браке с уровнем удовлетворенности браком. Удовлетворенность мужчин своим браком значимо коррелирует с тремя сферами индивидуальных ценностей. Наиболее высок коэффициент корреляции между удовлетворенностью браком и сферами «Красота природы и искусства» $(0,42)$, «Творчество» $(0,44)$. Корреляция прямая, что означает, что чем более выражены переживания и принятие мужчинами этих ценностей, тем выше вероятность того, что они будут удовлетворены своим браком. Стоит обратить внимание на коэффициент обратной корреляции «Материально-обеспеченная жизнь» $(-0,42)$.

Коэффициенты корреляции между индивидуальными ценностями и удовлетворенностью

Таблица 4. браком у мужчин и женщин, находящихся в браке

\begin{tabular}{|l|c|c|c|c|c|c|c|c|c|c|c|c|}
\hline & 1 & 2 & 3 & 4 & 5 & 6 & 7 & 8 & 9 & 10 & 11 & 12 \\
\hline Мужчины & 0,04 & 0,05 & 0,1 & 0,42 & $-0,2^{*}$ & $-0,42$ & $-0,22^{*}$ & 0,08 & $0,26^{*}$ & $-0,14$ & $-0,3$ & 0,44 \\
\hline Женщины & $-0,2^{*}$ & 0,07 & $0,2^{*}$ & $0,28^{*}$ & $-0,5$ & $-0,02$ & 0,18 & $-0,14$ & $0,28^{*}$ & $-0,17$ & $-0,45$ & 0,45 \\
\hline
\end{tabular}

Таблица 5.

Коэффициенты корреляции между семейными ценностями и удовлетворенностью браком у мужчин и женщин, находящихся в браке

\begin{tabular}{|l|c|c|c|c|c|c|c|}
\hline & 1 & 2 & 3 & 4 & 5 & 6 & 7 \\
\hline Мужчины & 0,16 & 0,09 & 0,04 & $0,21^{*}$ & $-0,2^{*}$ & 0,04 & $0,2^{*}$ \\
\hline Женщины & 0,03 & $0,22^{*}$ & $-0,11$ & 0,16 & 0,19 & 0,18 & 0,06 \\
\hline
\end{tabular}


Представленные данные свидетельствуют о различиях в принятиях ценностей между мужчинами и женщинами. Удовлетворенность женщин своим браком, как и мужчин, значимо коррелирует с тремя сферами индивидуальных ценностей. Наиболее значимый коэффициент корреляции между удовлетворенностью браком и ценностью «творчества» $(0,45)$. В этом случае корреляция прямая, и чем больше эксплицировано принятие и субъективное переживание женщиной этой ценности, тем выше удовлетворенность своим браком.

Еще два значимых коэффициента обуславливают отношения между индивидуальными ценностями и удовлетворенностью браком, в ценностях «Счастливая семейная жизнь» $(-0,45)$ и «Любовь (духовная и физическая близость с любимым человеком)» $(-0,5)$. Коэффициент обратный, из чего можно заключить что, чем более выражены эти ценности, тем менее женщины удовлетворены своим браком.

Таким образом женщины более удовлетворены своим браком, в котором они могут заниматься творческой деятельностью. Но в то же время они имеют меньшую «Включенность» В счастливую семейную жизнь и любовь.

В связи с тем, что критические значения коэффициента корреляции Пирсона для 120 человек равен 0,20, то есть еще несколько корреляционных связей, которые могут считаться как значимые, но имеют низкую частотHOCTb.

У мужчин это сферы: - «Любовь» $(-0,2)$; - «Познаний (возможного расширения своего образования, кругозора, общей культуры, а также интеллектуального развития)» $(0,26)$; - «Наличие хороших и верных друзей» $(-0,22)$. Это говорит о том, что при возможности большей проявленности этой ценности повышается и уровень удовлетворенности браком.

У женщин сферы: - «Активная деятельная жизнь» $(-0,2)$; - «Интересная работа» $(0,2)$; - «Красота природы и искусства» $(0,28)$; сфера «Познаний» $(0,28)$. Коэффициенты корреляции прямые и обратные, что можно интерпретировать так, что женщины более удовлетворены своим браком, в котором они могут заниматься интересной работой, иметь возможность интеллектуального развития и созерцать красоту природы и искусства. Но в то же время они имеют меньшую «включенность» в активную деятельную жизнь.

Последний этап исследования заключался в выявлении связи показателей семейных ценностей мужчин и женщин в браке с уровнем удовлетворенности браком. Достоверный коэффициент корреляционных связей по- казателей семейных ценностей и уровнем удовлетворенности браком отражен в табл. 5.

У мужчин удовлетворенность браком значимо коррелирует с тремя видами семейных ценностей. Положительная корреляция не высокого достоинства уровня удовлетворенности браком и таких семейных ценностей как «родительско-воспитательская» $(0,21)$ и «внешняя привлекательность» $(0,2)$. Это может свидетельствовать о том, что чем выше проживание отцовской, родительской роли, тем выше уровень удовлетворенности браком. Однако есть еще один коэффициент обратной корреляции, это «соотнесенность удовлетворенности браком» и семейной ценности «Социальная активность» $(-0,2)$. Это может значить что, для удовлетворенности свои браком мужчине не требуется социальная активность.

Совсем по-другому выглядит ситуация с соотнесённостью удовлетворенности брака с семейными ценностями у женщин, находящихся в браке. У женщин, находящихся в браке всего одна слабовыраженная корреляционная связь сферы семейной ценности «Личностная идентификация с супругом» $(0,22)$. Таким образом и в этом случае можно сказать, что, возможно, для женщин важно психологически «присоединяться» к своему партнеру, и чем выше эта связь, тем больше удовлетворенность своим браком.

Таким образом, анализируя результаты исследования, мы пришли к следующим выводам: - мужчины более довольны своим браком, чем женщины. Между тем, для мужчин, как и для женщин, является значимым психологическая включенность в партнера, реализация в сфере родительства, поддержка со стороны партнера и возможность социальной активности; - существуют значимые корреляционные связи между характером соотношения определенных сфер жизни, как ценностью с доступностью их реализации и семейными ценностями с удовлетворенностью браком у мужчин и женщин, находящихся в браке; - удовлетворенность браком у мужчин более вероятна, если в ней присутствует творческая деятельность и возможность интеллектуального развития, есть вероятность созерцать красоту природы и искусства. В то же время, чем больше внимания мужчины и проживают отцовскую, родительскую роль тем более вероятность быть удовлетворенным своим браком; - для женщин важно заниматься интересной работой, творческой деятельностью, интеллектуально развиваться и созерцать красоту природы и искусства. Но в то же время они имеют меньшую «включенность» в активную деятельную жизнь, счастливую семейную жизнь и любовь. Для женщин, находящихся в браке важно психологическое присоединение к партнеру, и чем выше эта связь, тем больше удовлетворенность браком. 


\section{ЛИТЕРАТУРА}

1. Алешина Ю.Е. Индивидуальное и семейное психологическое консультирование: практическое пособие. М.: Класс, 2000. $208 \mathrm{c}$.

2. Баландина Л.Л. Удовлетворенность браком в системе детско-родительских отношений // Вестник Пермского государственного гуманитарно-педагогического университета. Серия №1. Психологические и педагогические науки. 2014. С. 125-136.

3. Волкова А.Н. Социально-психологические факторы супружеской совместимости: Автореф. канд.дис. Л., 1979. 32с.

4. Волкова А.Н. Методические приемы диагностики супружеских затруднений // Вопросы психологии. 1985. № 5 С. 110-116.

5. Гурко Т.А. Брак и родительство в России. М.: Институт социологии РАН, 2008. 325 с.

6. Гурко Т.А. Теоретические подходы к изучению трансформации института семьи // Социологический журнал. 2020. Т. 26. № 1. С. $31-54$. DOI: 10.19181/socjour.2020.26.1.7052

7. Крапивка И.А. Ценностные ориентации в семейной жизни // Теория и практика общественного развития. 2010. № 4. С. 51-54.

8. ииселева Е.В. Семья как социокультурная ценность // Вестник славянских культур. 2016. С. 76-83.

9. Котельникова Ю.Е. Психологические факторы удовлетворенности браком в молодых семьях // Вопросы науки и образования. 2018. № 4 (16).

10. Coontz S. The way we never were: American families and the nostalgia trap. Revisited dated. N.Y.: BasicBooks, 2016. 576 p. D0l: 10.1086/ahr/98.5.1667

11. Coontz S. Revolution in intimate life and relationships // Journal of Family Theory \& Review. 2015. Vol. 7. No. 1. Pp. 5-12.

12. Шаваева 0.А. Трансформация системы семейных ценностей в современную эпоху // Политематический сетевой электронный научный журнал Кубанского государственного аграрного университета. 2014. № 02. С. 1-13.

13. Фанталова Е.Б. Диагностика и психотерапия внутреннего конфликта. Самара: БАХРАМ, 2001. 128 с.

() Бугаева Анна Михайловна (kalinskaia@mail.ru).

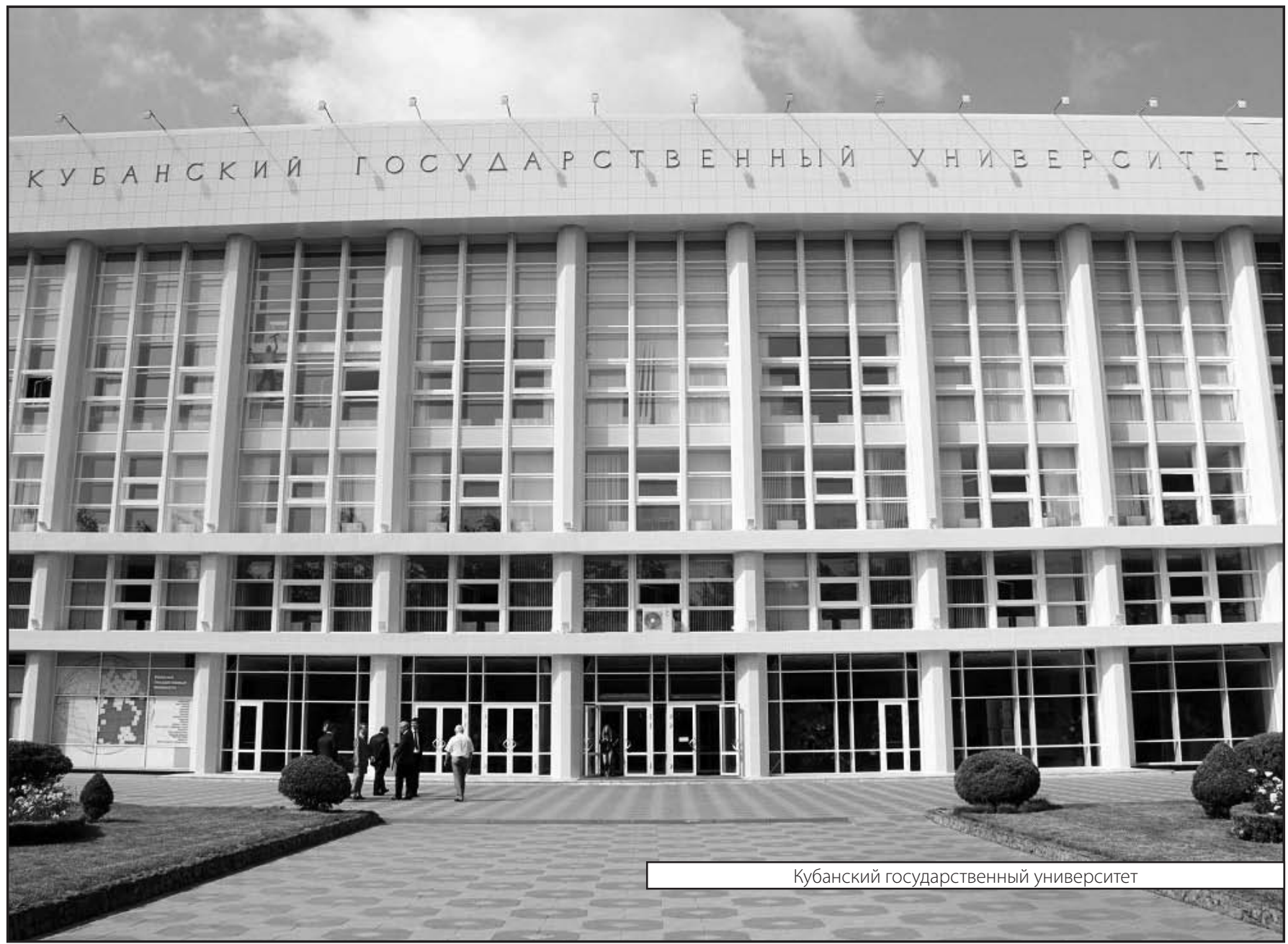

